\title{
THE LABORATORY DIAGNOSIS OF PREGNANCY
}

By HeRTa Schwabacher

Group 9 Laboratory, Watford, Herts.

No pregnancy diagnostic laboratory is in a position to undertake tests for pregnancy to satisfy the natural desire of every woman to know the truth as soon as possible. It is desirable that a healthy married woman be guided by her medical officer to await his diagnosis in the consulting room. The unmarried mother, however, should have the advantage of laboratory diagnosis. Here early diagnosis is a definite advantage in making re-adjustments in social and domestic life.

Medical conditions for which early diagnosis is sought are suspected hydatidiform mole, tubular gestation, abortion, abdominal tumours associated with amenorrhoea, amenorrhoea associated with an anaemia or endocrine dystrophy, teratoma of the testes and, lastly, suspected pregnancy in a tuberculous patient or a cardiac patient. It is obvious that the mother's life would be jeopardized if pregnancy were allowed to continue in the last two conditions.

Laboratory tests which have been evolved are either quantitative biochemical estimations or biological assays.

The disadvantages of the chemical tests are twofold. Firstly, none of the chemical reactions is as accurate as the better established biological tests and, secondly, the chemical tests are laborious and time-consuming in their technique. Voge (1929) introduced the bromine test for the estimation of histidine excreted during pregnancy. The technique was modified later by Kapeller-Adler (1934) and by Visscher and Bowman (1934), but the accuracy rarely exceeded 80 per cent. in any series of tests. Colorimetric determination of oestrogens in the urine have been attempted by Guterman (1945), but his claims of 93 per cent. accuracy have not been confirmed by later workers Reinhart and Barnes (r946), who obtained a 25 per cent. error.

The only reliable pregnancy tests are biological and are based on the enormous increase in the amount of gonadotrophic activity during pregnancy. The amount of chorionic gonadotrophin (C.G.) excreted usually reaches a maximum between the sixth and twelfth weeks and then rapidly falls to about io per cent. of the maximum by about the sixteenth week and remains at this level till a few days after parturition (Fig. I). It.is important to $\overrightarrow{\vec{\omega}}$ know the shape of the curve of output of the activity with each stage of gestation. The clinician can then more reliably interpret the result of the test. A weak positive, for example, around the three months stage might suggest treatment for $\omega$ threatened abortion. A very strong positive in $\mathrm{O}$ dilution of $\mathrm{r} / \mathrm{r} O$ and higher of the extracted prin- $\omega$ ciple from urine would indicate hydatidiform mole. N

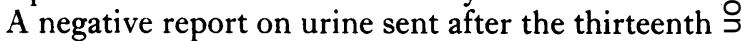
week may mean that the patient was excreting less than 3,000 I.U. gonadotrophin per litre on the day of the test (Hobson, I955). The gonadotrophin, when extracted, will be just below the reacting dose for test animal, 70 I.U. for a 70-gm. Xenopu业 This can occur anywhere between conception ans the twelfth day of pregnancy and again betwe the thirteenth week of pregnancy and parturition.

The four pregnancy tests which have been recognized as yielding an adequate standard of test accuracy are :

I. The Ascheim-Zondek, using immature female mice.

2. The Friedman, using immature female rabbits.

3. The Hogben ovulation, using mature female Xenopus toads.

4. The Galli Mainini spermiation, using mature toads.

It must be stressed that these tests are not, in fact, tests for pregnancy, but tests detecting the presence of relatively large amounts of gonado- 0 trophin from living chorionic cells. All four tests $>$ will give a positive result in normal pregnancy, in cases of hydatidiform moles and chorionic epi- $\bar{N}$ thelioma for periods up to about ro days after an $\sigma$ abortion if placental tissue is still retained.

I. Ascheim and Zondek (1928) based their test N్ట on the discovery that pregnancy urine contains aO substance which is gonadotrophic when injected into mice. This test has been modified by different $\frac{}{\square}$ workers, but the technique used in the Edinburgh $\stackrel{?}{\rightarrow}$ Pregnancy Diagnostic Laboratory is as follows: 0 Take 30 c.c. from the first sample of urine collected 
Chorionic Gonadotropin (c.e) Exeretion during Anegneney.

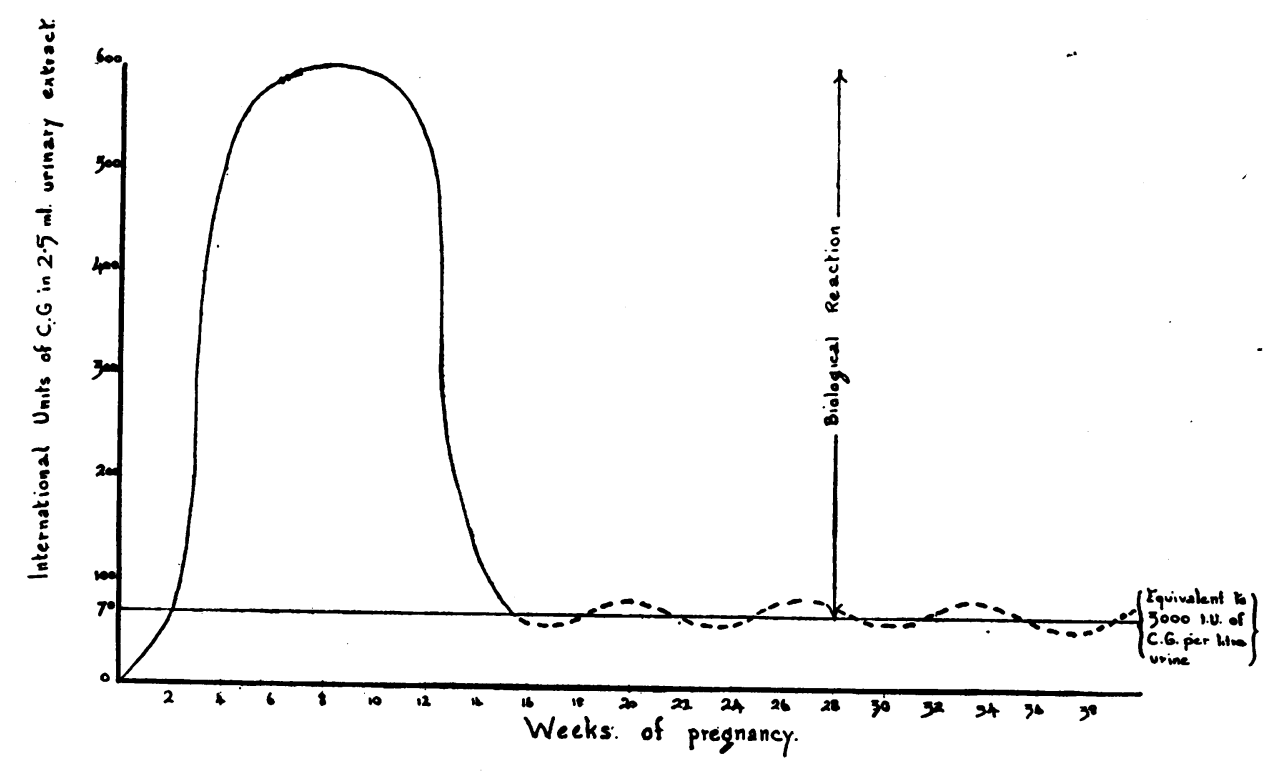

FIG. 1.-Gonadotrophin excretion curve in pregnancy.

in the morning. Add four drops of 20 per cent. thymol in alcohol to prevent bacterial growth during the three days the specimen is kept in a refrigerator.

Four infantile female mice 6 to $8 \mathrm{gm}$. in weight, three to four weeks old, are injected with the urine to be tested. Each mouse is given 0.5 c.c. each day for three days. If the ovaries and uteri are normal, the result is recorded as negative. If not normal, three different structures may be seen (see Plate $X$, Dukes, 1939).

I. Enlarged follicles associated with enlargement of the uterus.

2. Corpora lutea may be recognizable, especially with a lens.

3. Haemorrhagic follicles may be large and easily seen, but often have to be carefully looked for.

The first reaction of large follicles is not, if present alone, diagnostic of pregnancy, but occurs with urines from patients presenting histories of early menopause, severe anaemias and carcinoma of the uterus. It is due to FSH or oestrogens in the urine and is found in the later stages of pregnancy. A further specimen at a later date is requested if this reaction is found alone.

The presence of corpora lutea, together with blood spots in one or more mice, denotes a definite positive result. Such a positive result is obtained in cases where chorionic elements are in biological contact with maternal tissue, also in carcinoma of the ovaries and testes. The accuracy of this pregnancy test estimated on 20,000 tests per annum is 99.5 per cent.

2. Friedman (1929) relied on the fact that rabbits ovulate only when their ovaries are specifically stimulated. This occurs after mating or owing to female rabbits 'jumping' one another. Female rabbits must consequently be kept in separate cages one month before use to ensure that at the time of the test the ovaries do not contain any ruptured follicles and that the animals are not pregnant.

To 50 c.c. of urine is added 50 c.c. rectified spirit and the mixture allowed to stand a few minutes. A precipitate is formed which consists of inactive material and this is centrifuged off and discarded. Another I50 c.c. of rectified spirit is added to the mixture and this brings down a precipitate which contains the active substance. This precipitate is centrifuged off and extracted with ether to remove toxic substances and the remaining solid matter is dissolved in 5 c.c. of saline; 3 c.c. of this solution are injected intravenously and the animal operated on 24 hours later. In a few cases the reaction is doubtful in 24 hours and then the remaining 2 c.c. of extract are injected and the animal operated on after a further 24 hours.

A positive result is returned if one or more 
ovulated follicles are seen, or if one or more haemorrhagic follicles are present in one or both ovaries (see Plate XI, Dukes, I939).

In some laboratories 8 to ro c.c. of crude urine is injected intravenously and the rabbit sacrificed after 48 hours.

3. The Hogben test. Hogben was interested in the colour change of animals and while in South Africa in 1927 investigated the chromatic behaviour of the indigenous toad, Xenopus laevis. This animal is purely aquatic and turns dark if kept in water in a black container and becomes pale if placed in water in a white container. The eye was found to be the receptor for this response, the pituitary gland suspected as a mediator in the mechanism. When the pituitary gland was removed the operated animal remained pale even in a black background and the ovaries atrophied in a few weeks. To prevent their atrophy Hogben injected ox pituitary extracts. Not only were the ovaries regenerated, but ovulation and extrusion of eggs into the water was observed. Xenopus have cilia the whole length of the oviduct, so that any eggs ejected from the ovary at ovulation are automatically extruded from the body by ciliary action (Fig. 2). This animal conveniently fails to ovulate when kept in captivity. The reliability of this animal's response to C.G. depends on the husbandry it receives. Well-fed animals between 60 to $100 \mathrm{gm}$. are used. They must respond to 70 I.U. of chorionic gonadotrophin. Toads are used three times with an interval of ro days and then rested one month. This means that a single toad is used 18 times a year. The method of keeping these animals in correct rotation has been described by Schwabacher (1950) and Hobson (1952). Xenopus is kept in water at $22^{\circ} \mathrm{C}$. and fed once a week with chopped ox liver.

By means of the Scott technique (I940) $60 \mathrm{ml}$. of urine are concentrated into $5 \mathrm{ml}$. of extract. One toad only is used for each test and receives $2.5 \mathrm{ml}$. of extract into the dorsal sac. If the toad ovulates within 24 hours the result is recorded as positive. If, however, there is no ovulation in 24 hours, a second toad is injected with the remaining $2.5 \mathrm{ml}$. of the same extract. If both toads are negative 48 hours after the beginning of the test the result is reported negative. Hence with a strongly reacting urine the result of the test can be given in 24 hours, but a negative reaction is not reported until 48 hours.

We no longer seek confirmation from the doctor for our tests reported positive. We take it that an egg denotes the presence of chorionic epithelium. It is our routine to send out cards enquiring whether our negative tests are correct two months after the test has been made. This interval allows time for clinical evidenee of preg-

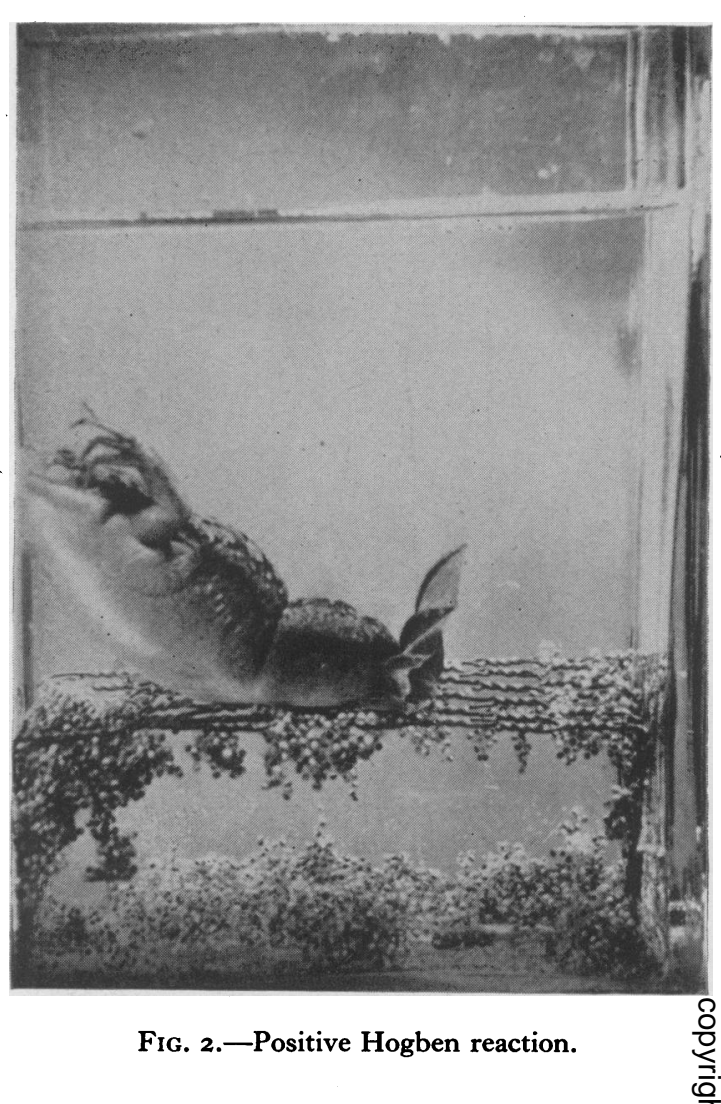

nancy to be well established. Schwabacher (1950) reported 99.48 per cent. possible accuracy and this figure compares favourably with the 24,000 tests per annum performed in Edinburgh, where an accuracy of 99.8 per cent. is achieved (Hobson, 1952).

4. The Spermiation test described by Galli Mainini (1947) has come into vogue in every country where toads are indigenous. Fraser (1950) reviewed the literature which had been produced in 26 species of amphibia. Not all species are suitable, as some animals spermiate naturally. This was found to be the case in Xenopus laevis (Schwabacher et al., 1956). Favourable reports on the use of Bufo bufo for pregnancy tests have been published in this country by Klopper and Frank (1949), Law (1949), Frazer and Wohlzogen (1949, 1950), Ferreira (1954), Haines and Ferreira (1949, 1954), Schwabacher, Elkan and Scott (1956). Urinary chorionic gonadotrophin is extracted by Scott's technique and $0.5 \mathrm{ml}$. injected into the dorsal sac. The cloacal fluid is examined three to six hours after injection. It is important that the final reading should be at least six hours after injection, since positive results were found to appear after the fifth hour and it is not generally practicable to increase the time still further if the 


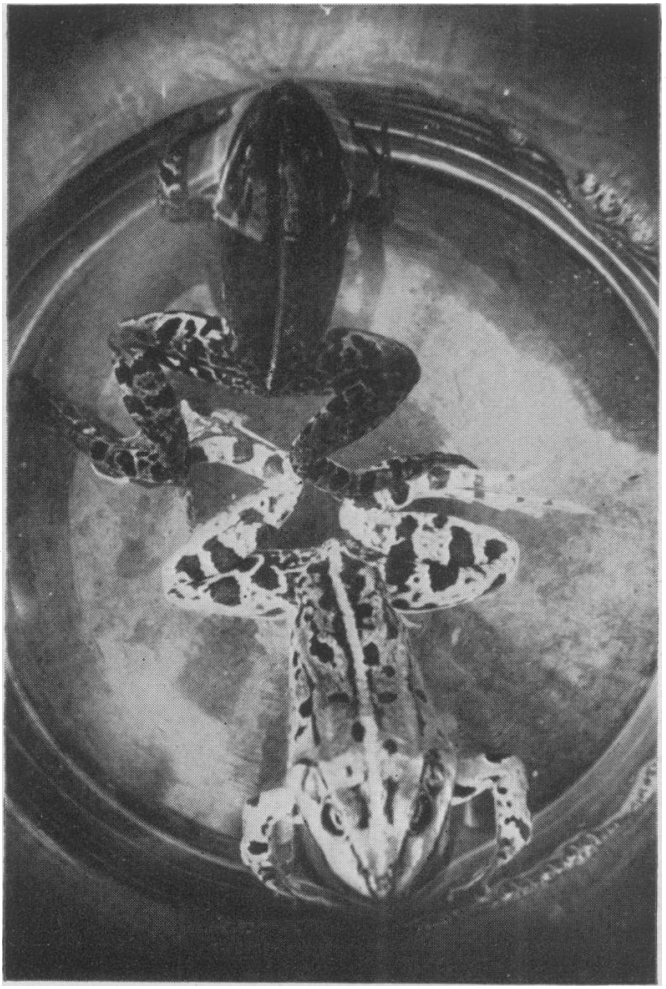

FIG. 3.-The normal dark toad together with the pale hypophysectomized toad.

urines are to be received, processed and injected on the same day. The method of housing Bufo is described by Law (1949). We have not been successful in maintaining the Bufo colony on fly larvae and meal worm, but found the animals maintain in good condition when fed on live Lucilia (blue-bottle fly). Elkan (1953) published a method of breeding flies as food for amphibia during summer and winter months. Each Bufo is not subjected to test more than 18 times a year and kept in rotation similar to Xenopus.

Other animals which have been used with less success for the early diagnosis of pregnancy are the rat and the hypophysectomized frog and toad.
The rat ovarian-hyperaemia test. Zondek (1926) observed that after treatment with gonadotrophin the ovaries of immature rats show a recognizable hyperaemia. Reiprich (1933, 1934) utilized this reaction as a pregnancy test. The bibliography of the evaluation of this test has recently been recorded by Elek (1955). The condemning factor for the rat as a test animal is that false positive results are obtained. This is not due to the injection of urine; uninoculated control animals may yield a positive picture.

The hypophysectomized frog or toad. Hogben and Winton (1923) described the technique of removing the pituitary body and noted that as a result the skin of the animal changed to a lighter colour (Fig. 3). This lighter hue remained permanent even when the animal was transferred to a dark background. Use was made of this observation by Konsuloff (1934). He found that within a matter of minutes after the injection of pregnancy urine the pale skin of the hypophysectomized toad or frog darkened.

The colour change is due to the expansion of melanophore cells, which can be seen easily in the web of the foot (Hogben and Winton, 1922). Landgrebe and Waring (1941, 1943, 1944) showed that the pars intermedia of the hypophysis elaborates the specific melanophore excitant. The injection of gonadotrophic extract from pregnancy urine will cause the melanophore cells to expand and the degree of expansion can be compared to the melanophore index chart given by Hogben and Slome (193I) (Fig. 4). In our experience (1956) the injection of known pregnancy urines yielded unexpected failures in the Konsuloff and melanophore expansion reactions in frogs where the pituitary appeared to have been successfully removed. Furthermore, when one takes into account the time required to prepare the animal prior to inoculation, this test is no quicker than the spermiation reaction.

\section{Discussion}

It has been shown that the reactions in the hypophysectomized toads and frogs are unsuited for pregnancy diagnosis. The occu rrence of false

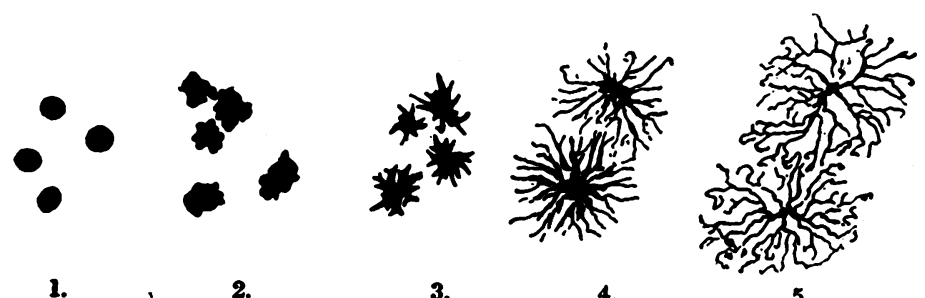

Fig. 4.-The Melanophore index. 
positives and false negatives in the rat test places it at a disadvantage over the ovulation and spermiation, Ascheim-Zondek and Friedman tests, where errors are confined to false negatives.

The choice of test animal depends on the number of tests the laboratory has to undertake.

The Ascheim-Zondek test performed on four mice diminishes the chance of error. (Two animals are used in the Hogben reaction, one toad for the spermiation and one rabbit for the Friedman test.) As immature mice have to be available and multiple manipulations are necessary over a period of four days, this test has been superseded by one of the following three:

The Friedman test is usually performed where a very occasional pregnancy test is requested. The cost of the rabbit limits its use.

The spermiation reaction is the test of choice in a laboratory not having to undertake more than a few dozen tests a day. The animals are indigenous here, can be kept healthy and used repeatedly. The test, therefore, is both cheap, reliable and the result is reported on the day of receipt of the pregnancy urine.

The Edinburgh Pregnancy Diagnostic Laboratory established that the Hogben test is more rapid, less expensive and more accurate than the Friedman and Ascheim-Zondek test (Crew, r939; Landgrebe, 1939). The injected toad is placed on a platform in its test jar. The floor of the jar is examined for eggs macroscopically at 24 and, if necessary, at 48 hours. The speed at which a large series of reactions can be read makes this animal the choice for a Central Pregnancy Diagnostic Laboratory. In cases where surgical procedure depends on the result of the pregnancy test both the spermiation and ovulation tests are set up. The result of the spermiation reaction is communicated on the day the specimen is received; the final report of both tests given on the following day.

The occurrence of false positive reactions due to retained products of conception after parturition has already been mentioned. During six years the Watford Pregnancy Diagnostic Laboratory has performed some 60,000 tests. Each year there have been about 50 per cent. positive and 50 per cent. negative reactions. On two occasions practitioners have queried the positive result. There is no guarantee that the return of menstruation was not associated with an abortion or that, despite all cleaning precautions, a Xenopus egg from a positive test had adhered to the test jar and been carried over to a negatively reacting toad. The Edinburgh Pregnancy Diagnostic Laboratory, undertaking twice this volume of work, have had no false positive reactions.

$A$ false negative reaction in a fully sensitized toad is an indication of too few active chorionic cells $\frac{0}{0}$ False negative results occur :

(a) During the first two weeks of pregnancy befor the peak period of clorionic gonadotrophin excretion is reached.

(b) From the thirteenth week of pregnancy onwards, when the urine may contain less than $3,000 \stackrel{5}{9}$ I.U. of chorionic gonadotrophin per litre.

(c) In ectopic gestation or threatened abortion and also in renal disease, where the excretion of chorionic gonadotrophin may be impaired.

(d) In hydatidiform moles, although the expelled mass may be covered with vesicles, in utero insufficient active cells may be embedded in the:wall of the uterus to liberate sufficient circulation $\vec{\omega}$ of chorionic gonadotrophin for a positive reaction. It is of interest here to point out that during theo peak of gonadotrophin excretion, second to thir -3 . teenth week of a normal pregnancy (or six to $18 \mathrm{~N}$ weeks after last menstrual period), it is possible to obtain a positive biological reaction in a $I$ in 100 or even $I$ in $r o o$ dilution of extract. Hence not until ${ }_{0}^{\omega}$ after this period can a reaction in these dilutions ${ }^{N}$ be diagnostic of molar pregnancy. A positive reaction in $\mathrm{I}$ in 200 dilution or higher at any period $\vec{D}$ of gestation is suggestive of hydatidiform mole or chorionic epithelioma. The gonadotrophin content $\frac{C}{\omega}$ of cerebro-spinal fluid is never in greater concentration than that of urine; it is therefore ug $\overrightarrow{0}$ necessary to submit the patient to the discomforto

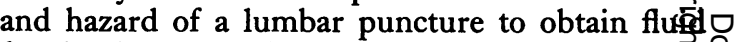
for the diagnosis of molar pregnancy.

(e) During radiation therapy of chorionic epithelioma. In three cases where metastases were confirmed at autopsy we repeatedly examined the $\stackrel{\square}{\stackrel{D}{\perp}}$ urine during life. Reactions varied from negative $\underset{\vec{P}}{\overrightarrow{0}}$ to positive in dilution of $I$ in 200 according to the $\frac{O}{3}$ activity of the neoplasm.

(f) Due to insufficient chorionic epithelial tissue in teratomatous tissue. Seminoma of the testes $-\overline{-}$ have, in our experience, failed to yield a positive 3 . Hogben reaction.

(g) Due to the excretion of subnormal amounts of chorionic gonadotrophin during pregnancy. These cases are rare, but those which have been followed up have had an uneventful pregnancy. 옥 Urines from these women have been tested on $\supset$ multiple occasions on Xenopus known to react to을. 50 I.U. of chorionic gonadotrophin. The speci- N mens therefore contained 2,000 I.U. per litre or less.

\section{Summary}

I. Biological tests for the diagnosis of earlyo pregnancy have been described.

2. Suggestions have been made for the choice $\stackrel{\mathscr{D}}{+}$ of the test animal, depending on the number of $\square$ tests the laboratory expects to undertake. 
3. Biological reactions in relation to normal pregnancy and pathological conditions have been discussed.

\section{BIBLIOGRAPHY}

ASCHEIM, S., and ZONDEK, B. (1928), Klin. Wschr., 7, 8. CREW, F. A. E. (1939), Brit. med. $¥$., $1,766$.

DUKES, C. E. (1939), 'Urine,' Oxford University Press.

ELEK, S. D. (1955), Brit. med. F., 2, 600.

ELKAN, E. (1953), Brit. ₹. Herpetology, I, 147.

FERREIRA, H. P.' (1954), Postgraduate med. $\mathcal{Y}$., 30, 355.

FRAZER, J. F. D. (1950), Brit. F. Herpetology, 1, 84:

FRAZER, J. F. D., and WOHLZOGEN, F. X.' (1949), Lancet, ii, 306.

FRAZER, J. F. D., and WOHLZOGEN, F. X. (1950), Brit. med. F.,

FRIEDMAN, M. H. (1929), Amer. F. Physiol., 90, 617.

GALLI MAININI, C. (1947), Semana Med. B. Aires, 1, 337.

GUTERMAN, H. S. (1945), \%. clin. Endocrinol., 5, 407.

HAINES, M., and FERREIRA, H. P. (1949), Nature, 164, 668.

HAINES, M., LAW, J. W., and AUDREY MAY (I954), $\mathcal{F}$. clin.

Path., 7, ${ }^{145 .}$
HOBSON, B. M. (1952), f. Obstet. \& Gyn., 59, 352.
HOBSON, B. M. (1955), Ibid., 62, 354.

HOGBEN, L., and SLOME, D. (1931), Proc. Roy. Soc. Ser B., I08, 10.

HOGBEN, L., and WINTON, F. R. (1922), Ibid., 93,318 .

HOGBEN, L., and WINTON, F. R. (1923), Ibid., 95, I5.

KAPELLER-ADLER, R. (1934), Klin. Wschr., 13,21 .

KLOPPER, A., and FRANK, H. (1949), Lancet, 11, 9.

KONSULOFF, S. (1934), Klin. W schr., 13, 490, 776.

LANDGREBE, F. W. (1939), $\dot{f}$. exp. Biol., 16, 89.

LANDGREBE, F. W., and WARING, H. (I94I), Quart. f. exp.

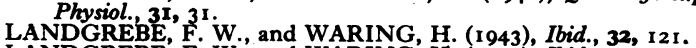

LANDGREBE, F. W., and WARING, H. (1944), Ibid., 33, $\mathrm{I}$.

LAW, J. W. (1949), Bull. Inst. Med. Lab. Tech., I4, 175 .

REINHART, H. L., and BARNES, A. C. (I946), Ұ. clin. Endocrinol., 6, 664

REIPRICH, W. (1933), Klin. Wschr., 12, 1441.

REIPRICH, W. (1934), Z. Geburt, Gynak., 109, 285.

SCHWABACHER, H.' (1950), Brit. med. $\dddot{y}$., 1i, 328 .

SCHWABACHER, H., ELKẢN, E., and SCOT'T, F. E. T. (1956), Medical Press 235, 5 I 3.

SCOTT, L. D. (1940), Brit. F. exp. Path., 21, 320.

VISSCHER, J. P., and BOWMAN, D. E. (1934), Proc. Soc. exp. Biol. N.Y., 3i, 460 .

VOGE, C. I. B. (1929), Brit. med. F., ii, 829.

ZONDEK, B. (1926), Z. Geburt. Gynak, 90, 372.

\section{PERIPHERAL VASCULAR DISORDERS}

(Postgraduate Medical Journal)

Price: 3s. 10d., post free

THE INVESTIGATION OF PERIPHERAL

VASCULAR DISORDERS

Peter Martin, V.R.D., M.Chir., F.R.C.S. (Ed.)

\section{PERIPHERAL ARTERIOGRAPHY AND} AORTOGRAPHY

Robert E. Steiner, M.B., Ch.B., D.M.R.,

F.F.R., and David Messent, M.B., F.R.C.S.

THE MEDICAL MANAGEMENT OF OBLITERATIVE ARTERIAL DISEASE OF THE LEGS

Robert Semple, M.D., M.R.C.P.
RAYNAUD PHENOMENON

R. P. Jepson, F.R.C.S.

COLlateral Circulation IN THE LIMB

C. J. Longland, M.V.O., M.S., F.R.C.S.

SYMPATHECTOMY AND PALLIATIVE OPERATIONS FOR OCCLUSIVE

ARTERIAL DISEASE

A. J. Slessor, M.V.O., F.R.C.S.

BLOOD VESSEL GRAFTING

C. G. Rob, M.C., M.Chir., F.R.C.S.

Published by

THE FELLOWSHIP OF POSTGRADUATE MEDICINE

60, Portland Place, London, W.1.

\section{RUTHIN CASTLE, NORTH WALES}

A Clinic for the diagnosis and treatment of Internal Diseases (except Mental or Infectious Diseases). The Clinic is provided with a staff of doctors, technicians and nurses.

The surroundings are beautiful. The climate is mild. There is central heating throughout. The annual rainfall is $\mathbf{3 0 . 5}$ inches, that is, less than the average for England.

The Fees are inclusive and vary according to the room occupied.

For particulars apply to THE SECRETARY, Ruthin Castle, North Wales. 